\title{
RECEPTÁCULO SEMINAL EM MITHRACIDAE: CARACTERIZAÇÃO MORFOLÓGICA E HISTOQUÍMICA DE MITHRAX HISPIDUS, OMALACANTHA BICORNUTA E MITHRACULUS FORCEPS (BRACHYURA)
}

\author{
Assugeni, C.O. ${ }^{1, *} \&$ Zara, F.J.Z. ${ }^{1}$ \\ ${ }^{1}$ Universidade Estadual Paulista (UNESP), Faculdade de Ciências Agrárias e Veterinárias de Jaboticabal (FCAV), \\ Departamento de Biologia, Laboratório de Morfologia de Invertebrados (IML). \\ *Autor correspondente: camila.assugeni@gmail.com
}

\begin{abstract}
Majoidea é um dos grupos de caranguejo com maior registro de competição espermática pela formação de estratos espermáticos no interior do receptáculo seminal (RS). Neste trabalho examinamos a anatomia e histoquímica do receptáculo seminal de fêmeas com ovário em vitelogênese de Mithrax hispidus (Herbst, 1790), Omalacantha bicornuta (Latreille, 1825) e Mithraculus forceps A. Milne-Edwards, 1875 com intuito de verificar ou não a ocorrência de competição espermática. Os espécimes foram coletados por meio de mergulho autônomo, posteriormente foram dissecadas e as amostras processadas conforme rotina para historesina. Para as três espécies de Mithracidae, o RS é dividido em duas regiões: a região de origem mesodérmica (dorsal) que consiste de um epitélio estratificado com células em descamação que caracteriza secreção do tipo holócrina. A região ectodérmica (ventral) é composta por um epitélio cúbico simples recoberto por uma cutícula. O oviduto abre-se na mesoderme em posição ventral, próximo à região de transição, formada por epitélio prismático, com cutícula. Esta região de transição mostra dobras mais acentuadas na face oposta ao oviduto, que podem auxiliar na fertilização devido à presença de musculatura externa. A vagina, contínua com a região ventral possui as mesmas características epiteliais cúbicas e simples. No lúmen do RS das espécies estudadas foram observadas massas espermáticas em formato circular relembrando espermatóforos coenospérmicos. O RS do tipo ventral seguiu o padrão mais comum encontrado em Majoidea, sendo a secreção produzida no mesmo composta de glicoproteínas, com polissacarídeos neutros. Os polissacarídeos ácidos, com provável função contra microorganismos, é proveniente do fluido seminal masculino. No RS das três espécies, não foram encontrados estratos espermáticos. Desta maneira, não pode-se inferir se estas fêmeas recebem material de mais de um macho e, caso aconteça, no momento da fertilização não ocorre a preferência de uso dos espermatozoides de um macho em relação a outro.Palavras-Chave: Majoidea, competição espermática, histologia, caranguejo-aranha.
\end{abstract}

Palavras-chave: Majoidea, competição espermática, histologia, Caranguejo-aranha.

Fonte de Financiamento: CNPq (Universal \#486337/2013-8); Ciências do Mar II (\#1989/2014-23038.004309/201451); BIOTA-FAPESP (\#2010/50188-8). 